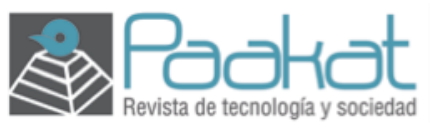

Paakat: Revista de Tecnología y Sociedad

e-ISSN: 2007-3607

Universidad de Guadalajara

Sistema de Universidad Virtual

México

paakat@udgvirtual.udg.mx

Año 12, número 22, marzo - agosto 2022

\begin{abstract}
Acción pública y telefonía comunitaria para la inclusión digital de comunidades rurales indígenas: el caso de San Pedro el Alto, Zimatlán, Oaxaca
\end{abstract}

\title{
Public action and community telephony for the digital inclusion of indigenous rural communities: the case of San Pedro el Alto, Zimatlán, Oaxaca
}

\author{
Minerva Vásquez Ramos* \\ https://orcid.org/0000-0002-4454-0442 \\ Universidad de la Sierra Sur, México \\ Diego Soto Hernández ${ }^{* *}$ \\ https://orcid.org/0000-0003-4768-9290 \\ Universidad de la Sierra Sur, México \\ Rafael Rentería Gaeta*** \\ https://orcid.org/0000-0001-8134-999X \\ Universidad de la Sierra Sur, México
}

[Recibido 12/8/2021. Aceptado para su publicación 18/1/2022]

DOI: http://dx.doi.org/10.32870/Pk.a12n22.674

\section{Resumen}

En la sociedad de la información, el núcleo que garantiza la igualdad en oportunidades y derechos es la inclusión digital. Sin embargo, en países como México, la brecha digital impide que miles de personas de comunidades rurales marginadas puedan integrarse a la era digital, situación que 
produce múltiples desigualdades. Este documento tiene por objeto difundir los resultados de un estudio de caso sobre la inclusión digital a través de la telefonía celular comunitaria (TCC) en la localidad de San Pedro el Alto, Zimatlán, Oaxaca, pionera en esta iniciativa. La investigación se inserta en el marco de la teoría de la acción pública, por lo que se aplicó un método mixto y una estrategia de triangulación metodológica que permitió combinar la información documental con la empírica para analizar: los factores habilitadores, del entorno y de la participación del modelo de acción pública adoptado, el contexto comunitario y el diseño, la implementación y la operación de este servicio de telefonía. Los resultados muestran que la participación social es el componente que tiene mayor incidencia en la implementación y operatividad del servicio de TCC. Al respecto, se concluye que este modelo de telefonía es una alternativa, con viabilidad política y económica, para la inclusión digital de comunidades rurales que han sido excluidas por el mercado de las telecomunicaciones.

\title{
Palabras clave
}

Inclusión social; cambio social; TIC; política digital; brecha digital.

\begin{abstract}
In the information society, the core that guarantees equal opportunities and rights is digital inclusion. However, in countries like Mexico, the digital divide prevents the insertion into the digital era of thousands of people from marginalized rural communities, a situation that produces multiple inequalities. The purpose of this document is to disseminate the results of a case study on digital inclusion through community celular telephony (CCT) in San Pedro el Alto, Zimatlan, Oaxaca, a pioneering in this initiative. The research is inserted in the framework of the public action theory, so a mixed method and a methodological triangulation strategy was applied that allowed combining documentary and empirical information to analyze: the enabling factors of the implemented public action model, the community context and the design, implementation and operation of this telephony services. The results show that social participation is the component that has the greatest impact on the implementation and operation of the CCT service. In this regard, it is concluded that this telephony model is an alternative, with political and economic viability, for digital inclusion of rural communities that have been excluded by the telecommunications market.
\end{abstract}

\section{Keywords}

Social inclusion; social change; ICT; digital policy; digital divide.

\section{Introducción}

En las sociedades contemporáneas, el uso masivo de las tecnologías de la información y la comunicación (TIC) tiene un impacto transformador en la cohesión social. En la actualidad, gran parte de las relaciones humanas (sociales, políticas, comerciales, laborales, sentimentales, etcétera) se valen de las TIC, pues permiten una comunicación e interacción remota en tiempo real. Estas ocupan un lugar central en varias actividades cotidianas, por lo que su impacto va más allá de lo instrumental, es decir, ya no se les concibe solo como herramientas de comunicación, sino que se asocian directamente a los procesos de socialización y a las relaciones de poder político y económico entre diversos actores y sectores.

La inclusión digital -entendida como el acceso y uso cotidiano de las TICabre la posibilidad de relacionarse, interactuar e intercambiar información y conocimientos; además, las herramientas tecnológicas crean diversos espacios 
virtuales que favorecen la participación y la inclusión social. Es por esto que la brecha digital -la desigualdad en el acceso y uso de las tecnologías- genera marginación e inequidad social, ya que no permite disponer de las oportunidades y los beneficios que ofrece lo digital.

A pesar de la expansión tecnológica, hasta la fecha no se ha logrado una cobertura universal que conciba un acceso generalizado a los servicios de telefonía e internet. Esta es la situación a la que se enfrentan varios países en vías de desarrollo (como México), donde existen mayores obstáculos para lograr la inclusión digital de todos sus habitantes, y de esta forma respetar el derecho a la igualdad de oportunidades y al de acceso de información.

Cabe destacar que varios gobiernos han impulsado políticas y estrategias para lograr la inclusión social y la transición a la Sociedad de la Información (SI) (Lemmens, 2006); se han realizado acciones para disminuir la brecha digital (Zambrano, 2009), lograr la expansión de la banda ancha para mejorar la conectividad (Jordán, Galperin y Peres, 2013), ampliar la oferta de servicios electrónicos (Kvasnicova, Kremenova \& Fabus, 2016), entre otras iniciativas. Pese a estos esfuerzos, las comunidades rurales de distintos países continúan con disparidades respecto al acceso a las TIC, lo que perpetúa los problemas de desigualdad social.

Partiendo de esta problemática, se desarrolló un proyecto para investigar la telefonía celular comunitaria (TCC) en la localidad rural de San Pedro el Alto, en el municipio de Zimatlán, Oaxaca, México. En este trabajo, dentro del marco de la teoría de la acción pública de Lascoumes y Le Galés (2013), se analizó la brecha digital en el contexto comunitario de la zona, así como la participación social organizada y la colaboración de actores sociales, públicos y privados. De estos últimos, se revisó especialmente el papel de Rhizomática $A$. C., que participó en el diseño e implementación de los servicios de TCC para la inclusión digital de esta localidad. El presente documento tiene como objetivo principal difundir los resultados de este estudio de caso.

Esta investigación se sustenta en argumentos teóricos que afirman que las TIC han sido un factor crucial en el surgimiento de un nuevo orden social: la SI, donde la esfera sociocultural y el sistema económico subyacen del uso masivo de tecnologías (como las computadoras, la telefonía y la internet), y del acceso a la información y el conocimiento (Serrano y Martínez, 2003).

En México, muchas localidades rurales de municipios del Sur, como Oaxaca, Guerrero y Chiapas, no tienen acceso a las TIC. Una de las razones tras esto es que los proveedores de los servicios de telefonía e internet son compañías privadas que se rigen bajo leyes de oferta y demanda, y ya que estas comunidades tienen escasa población, bajo poder adquisitivo y altos índices de pobreza, terminan siendo marginadas por estas compañías y no logran acceder a los servicios que ofrecen. Frente a esta realidad, en varias ocasiones son las propias 
comunidades las que buscan alternativas estratégicas para reducir la brecha digital que padecen.

La TCC en San Pedro el Alto es una de estas medidas, y cobra especial relevancia para el proyecto por tres razones: 1) se trata de una estrategia que surgió desde la sociedad civil organizada; 2) se implementó como una acción pública a través de la participación comunitaria; y 3) se da en una comunidad que está predispuesta a la participación y colaboración para obtener la prestación de servicios de telefonía e internet.

La estructura teórica que siguió la investigación se sustenta en las bases de la inclusión y la cohesión social, la acción pública y la colaboración social y la relación de estas con la inclusión digital y las potenciales soluciones a la brecha digital (para lograr una igualdad de oportunidades). De igual forma, se analizaron los factores habilitadores, del entorno y de la participación del modelo de acción pública adoptado en la localidad de San Pedro el Alto, el contexto comunitario y el diseño, la implementación y la operación de este servicio de telefonía.

\section{Referentes teóricos}

\section{Inclusión y exclusión social}

La inclusión y la exclusión social son proceso articulados que no pueden deslindarse, pues sus factores son interdependientes. Carbajal (2009) señala que el concepto de exclusión social refiere a una situación donde coinciden la insuficiencia de medios materiales, la falta de participación en el empleo y la incapacidad para acceder a bienes como la cultura, la educación, la sanidad o la vivienda. Por su parte, Travieso y Planella (2006) aseguran que es un fenómeno multidimensional que comprende factores psicológicos, psicosociales y especialmente culturales.

Siguiendo esta perspectiva, la exclusión social puede definirse como una situación social que impide lograr una mejor posición social, superar una situación desventajosa o disfrutar de un derecho al que se debiera tener acceso (Chuaqui, Mally y Parraguez, 2016). Esta multidimensionalidad propia del término, según Chuaqui, Mally y Parraguez (2016), comprende aspectos: económicos (patrimonio e ingreso), territoriales (el contexto geográfico, la infraestructura y los medios tecnológicos) y sociocultural (el estatus, los roles sociales, los aspectos étnicos y los factores de discriminación, entre otros).

En tanto a la inclusión social, Silver (2015) puntualiza que es un proceso relacional que se apoya de la interacción social y que propicia la solidaridad, la cohesión, el respeto mutuo y el sentido de pertenencia, así como el mejoramiento de capacidades, oportunidades y condiciones de vida en general. En otras palabras, la inclusión social es esencial para la integración social, entendida como 
el conjunto de factores que inciden en los lazos afectivos y en la formación de estructuras sociales, como la cultura, el lenguaje, los incentivos, el estatus y el liderazgo (Blau, 1960).

Barba (2011) menciona que "la integración social es la base funcional de la cohesión social y esta última subyace fundamentalmente de aspectos socioculturales y de la formalización normativa" (p. 71). El autor retoma las teorías de Durkheim al señalar que la cohesión social puede ser vista como solidaridad mecánica, fundada en creencias y prácticas comunes que fortalecen la identidad, la percepción de igualdad, la conciencia colectiva y la construcción de instituciones y estructuras sociales.

En ese orden de ideas, la inclusión social se sustenta de procesos que agrupan un conjunto de esfuerzos colectivos emprendidos en un contexto específico para incrementar las oportunidades de integración de las personas a la esfera social. La inclusión y la cohesión social se materializan a partir del comunitarismo, conceptualizado como el conjunto de normas y principios que determinan los comportamientos, las relaciones intra e intergrupales y los modos de actuar en la vida cotidiana: en el trabajo y en las relaciones sociales, económicas y afectivas (Camas, 2014, p. 51).

Otros aspectos fundamentales para la inclusión social son la participación social y la acción pública, factores que, por lo general, prevalecen en comunidades rurales. Por ejemplo, cuando estas poblaciones se enfrentan a problemas relacionados con la pobreza y marginación que viven, y por iniciativa propia se organizan para atenderlos. Esta sucedió en San Pedro el Alto, donde los habitantes se vieron obligados a implementar la TCC para reducir la brecha digital en la que se encuentra su comunidad.

\section{Acción pública y participación social}

La acción pública regularmente se asocia con el Estado y el gobierno; sin embargo, para Peters (2003) esta idea nos aleja de la concepción original. Público es aquello que le concierne al pueblo, por lo tanto, tiene que ver más con lo colectivo y comunitario que con lo gubernamental. Es así que, en la actualidad, lo público debe relacionarse, a la vez, con la acción del Estado y con el interés colectivo (Garzón, 2003). Lo público es el mundo y el espacio común que surge cuando las personas se agrupan y se organizan en torno al discurso y la acción (Esteban, 2016), y se caracteriza, en esencia, por la inclusión y la pluralidad, es decir, la coexistencia de semejanzas y diferencias y la búsqueda del bien común.

Con esto en consideración, la acción pública implica la solución conjunta gobierno-sociedad y decisiones colectivas para atender problemas de interés colectivo (Ruano, 2002). Se concibe como "la capacidad de definir metas colectivas, de movilizar los recursos necesarios para perseguirlas, de tomar las 
decisiones que impone su consecución y de asumir las consecuencias que de ella resulten" (Durán, 1999, citado en Amaya, 2010, p. 45).

Para Amaya (2010), la participación social y la colaboración constituyen la esencia y naturaleza de la acción pública, que se trata de una tarea estratégicamente organizada, en la que se involucran diversos actores y recursos para resolver un problema en común. Así, los teóricos de la acción pública consideran en primer orden los actores involucrados y sus intercambios, lo que permite centrar la importancia del individuo en la toma de decisiones, en las consecuencias de estas y en la solución de un problema.

La acción pública implica la interacción de diversos actores, individuales o colectivos, ${ }^{1}$ así como la intervención de distintos sectores: público, social y privado (Cabrero, 2009; Thoenig, 1997). Este intercambio tiene implicaciones económicas y políticas relacionadas con los bienes y recursos, el ejercicio del poder, los arreglos institucionales y el conjunto de normas y procedimientos que gobiernan las decisiones, las interacciones y la propia acción (Lascoumes y Le Galés, 2013).

En San Pedro el Alto, la TCC fue implementada con base en la participación y la colaboración de distintos actores (personajes del gobierno, agentes externos y los propios habitantes); esto toma parte de la teoría de la acción pública para contribuir a la inclusión digital, tanto en el modo de organizarse y colaborar, como en la actuación de los involucrados en este proceso comunitario. Para la investigación se aplicó un modelo interactivo de acción pública basado en el modelo histórico o tradicional de Jones (1970) y en el pentágono de la acción pública propuesto por Lascoumes y Le Galés (2013), que considera el análisis de cinco variables interrelacionadas: representaciones, actores, instituciones, procesos y resultados. Con el fin de lograr una mayor comprensión de la acción comunitaria, a la variable actores se agregó el factor de la participación social (ver figura 1).

Las representaciones son los marcos cognitivos que dan sentido a las acciones individuales y colectivas. Los actores pueden ser individuos o colectivos que forman parte de la comunidad y tienen determinados intereses materiales y simbólicos, así como recursos (económicos y políticos) y cierta autonomía para diseñar estrategias de acción y participar en ellas. Las instituciones son los marcos de acción, y se representan por normas, reglas, rutinas y procedimientos que orientan las interacciones de los actores. Los procesos están determinados por la combinación de las representaciones y las instituciones, mientras que los resultados son los efectos producidos a través de la acción pública, tanto en la organización como en los comportamientos de los actores, y el impacto que se consigue sobre el problema (Lascoumes y Le Galés, 2013, p. 20).

\footnotetext{
1 Uslaner y Conley (2003) señalan que el problema de la acción pública no reside en la participación de asociaciones o colectivos, sino en la capacidad de estos para albergar grupos heterogéneos en su interior.
} 
Figura 1. Modelo de acción pública

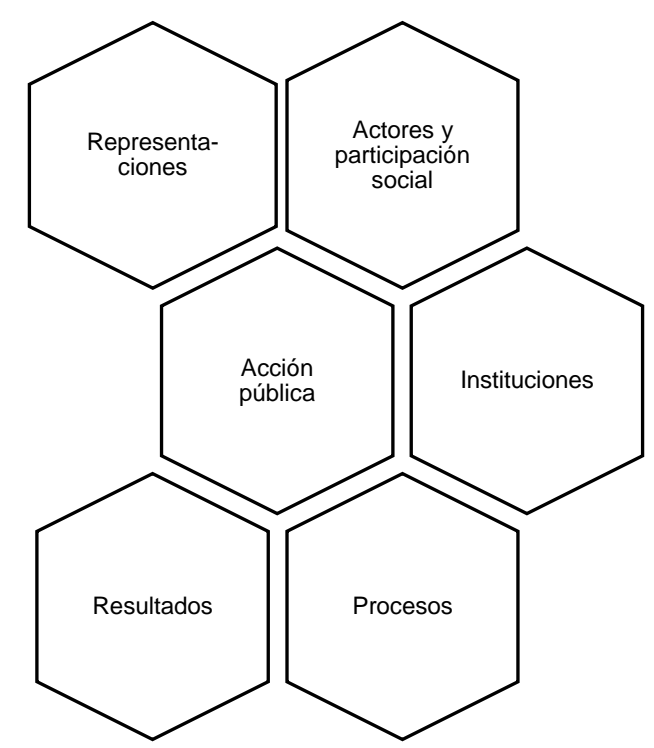

Fuente: elaboración propia con base en Lascoumes y Le Galés (2013).

Con estas precisiones, la participación social (agregada a la segunda variable) refiere el involucramiento de los actores individuales y colectivos en la acción pública, desde los acuerdos previos -el aporte de conocimientos y recursos, y el trabajo realizado- hasta la implementación y operación del sistema de TCC.

En el caso de estudio, esta participación es no convencional, porque no está subordinada al cumplimiento de normas formales. El contexto de la comunidad de San Pedro el Alto posibilitó la implementación de un modelo de acción colectiva, ya que esta pequeña localidad rural, aunque con graves problemas de pobreza y rezago social, se caracteriza por haberse regido históricamente por usos y costumbres, y por practicar la participación social y la colaboración como mecanismos tradicionales para resolver problemas comunitarios.

\section{Inclusión digital y brecha tecnológica}

La inclusión digital supone un constructo teórico-conceptual complejo, en el que resaltan la infraestructura tecnológica, la información, el sistema económico, la cultura y las instituciones. Se enfoca en el aprovechamiento de los beneficios de la SI y se concibe como una forma de inclusión social. Para la Unión Internacional de Telecomunicaciones (ITU, por sus siglas en inglés) la inclusión digital conlleva el empoderamiento y la igualdad de géneros (ITU, 2016).

Ramírez y Sepúlveda (2018) afirman que la inclusión digital no se reduce a la adopción, acceso y uso de las TIC, sino que se trata de un proceso que comprende el acceso físico e intelectual de las mismas, cuyo impacto social se traduce en igualdad de oportunidades para que las personas y las comunidades 
puedan participar, relacionarse y aprovechar los beneficios de la SI en todos los ámbitos, independientemente de las condiciones en las que se encuentren.

Para Thompson, Jaeger, Taylor, Subramaniam y Bertot (2014) la inclusión digital es el resultado de procesos emprendidos por entidades gubernamentales y no gubernamentales para cerrar la brecha y la alfabetización digitales, debido a que en los países en vías de desarrollo el primer obstáculo para la inclusión digital es precisamente la brecha tecnológica -el no acceso a las TIC (Hargittai, 2003) -, que se traduce en la marginación y la desigualdad en el acceso y uso de las tecnologías.

Para Keniston \& Kumar (2003) la brecha digital tiene cuatro dimensiones: a) económica, que subyace de la falta de recursos económicos para adquirir las TIC; b) lingüística, asociada con la hegemonía de lenguas dominantes como el inglés; c) tecnológica, relacionada con la falta de acceso a la industria de las TIC y la escasa conectividad de Internet; y d) cultural, relacionada con las capacidades, habilidades y culturas dominantes en la SI.

Aunado a esto, Selwyn (2004) menciona que la brecha digital no es un proceso lineal y presenta múltiples líneas desarticuladas entre sí, por lo que se podría decir que existen distintas brechas digitales: de acceso efectivo a las TIC en el hogar, el trabajo y la escuela; de uso de las TIC, en función de la utilidad y relevancia para el usuario; y de resultados e impactos, relacionada con actividades productivas, sociales y políticas.

\section{Telefonía celular comunitaria (TCC)}

Aunque no hay un concepto generalizado de la TCC, Huerta y Lawrence (2017) proponen una serie de características que permiten diferenciar este servicio de otras modalidades. Gracias a estas, se puede decir que la TCC es un modelo específico de telefonía elaborado con base en recomendaciones de la UIT para el desarrollo de políticas públicas y de las TIC en comunidades rurales e indígenas.

El modelo se diseñó al considerar los niveles socioeconómicos de los usuarios y se opera a través de una red local administrada por una asociación cooperativa de las propias comunidades. "Las llamadas nacionales se hacen a través de internet, servicio que es proporcionado por una microempresa, y el servicio de voz por Internet (VoIP) es proporcionado por un pequeño operador, que se conecta a la red global de telefonía" (Huerta y Lawrence, 2017, p. 8).

La TCC comprende cuatro elementos: 1) la base organizativa; 2) la base tecnológica; 3) la base económica; y 4) la base técnica. El primer punto corresponde a la parte social comunitaria responsable de la administración y operación del servicio; por su parte, el segundo contempla que la tecnología utilizada sea accesible en términos económicos (para su adquisición), así como a 
los técnicos encargados de su operación y mantenimiento. El tercer elemento comprende el esquema de negocios, acorde con las condiciones económicas de los usuarios; y en el cuarto se integra la infraestructura material y los conocimientos técnicos del personal para la operación y el mantenimiento del servicio (Huerta y Lawrence, 2017).

Otro aspecto importante para los autores es el marco normativo conformado por las pautas internas de las comunidades (usos y costumbres, sistema de cargos, asamblea comunitaria, bienes comunales, etcétera) y las regulaciones externas que protegen los derechos y la autonomía interna de los pueblos y comunidades indígenas -estipuladas en el segundo artículo de la Constitución Federal, en el Convenio 169 de la Organización Internacional del Trabajo y en la legislación local-, así como las regulaciones específicas en materia de telecomunicaciones. Estos aspectos en su conjunto permiten la autogestión del servicio.

El modelo de TCC se despliega a través de una macro red híbrida integrada por tres redes: una red local comunitaria, que opera en el espectro de banda de $850 \mathrm{MHz}$; una red de transporte, que contiene un sistema de enlace remoto wifi que pertenece al proveedor de servicios de Internet; y el Internet Service Provider (ISP) de enlace a la red troncal de un concesionario de red pública de telecomunicaciones al cual se le deben pagar los servicios de interconexión (Huerta y Lawrence, 2017, p. 15).

\section{Contexto comunitario: San Pedro el Alto, Zimatlán, Oaxaca}

Desde hace más de dos décadas, México ha implementado políticas públicas de inclusión digital. En el Plan Nacional de Desarrollo 2001-2006 se establecía la estrategia de "ampliar la infraestructura básica para la transmisión digital con el fin de ampliar su cobertura a localidades rurales o urbanas de alta marginación", para reducir la brecha digital y lograr la inclusión social de los grupos más rezagados (Diario Oficial de la Federación, 2001).

Si bien el concepto rural es difícil de definir, porque involucra varios elementos, puede lograrse una caracterización de la ruralidad al considerar los siguientes factores: asentamientos humanos con baja densidad poblacional en un paisaje dominado por elementos naturales, como bosques, montañas, pastos, selva, desierto, etcétera (Ashley \& Maxwell, 2001), donde la actividad productiva más importante es la agricultura o el trabajo del campo (Abdulwakeel, 2017), y prevalece un ambiente hogareño basado en la ascendencia, en la herencia cultural y, principalmente, en la vida comunitaria (Chigbu, 2013).

A esto deben aunarse otras características; en países en vías de desarrollo, las comunidades rurales carecen de planificación (Chigbu, 2013), por lo que permanecen aisladas territorialmente. Esto ocasiona problemas de acceso a los 
servicios básicos, falta de oportunidades de empleo no agrícola y privación de infraestructura para la comunicación, la educación, los sistemas financieros y de salud, entre otros.

De acuerdo con el Censo de Población y Vivienda 2010, realizado por el Instituto Nacional de Estadística y Geografía (INEGI), en México existían más de 50000 localidades rurales $^{2}$ que no contaban con acceso a servicios de telecomunicaciones, lo que representaba el $16.42 \%$ de la población total del país (INEGI, 2013). En 2013 el Gobierno Federal impulsó nuevas medidas en aras de disminuir esta cifra, una de ellas fue reconocer el acceso a las TIC y la inclusión digital como derechos constitucionales (Alva de la Selva, 2015). Estos esfuerzos no han sido suficientes y la reducción de la brecha digital no ha sido del todo efectiva, sobre todo en regiones que presentan altos índices de pobreza y marginación, como Oaxaca.

Para 2010, Oaxaca contaba con 4132148 habitantes (3.3\% de la población del país), $51 \%$ de los cuales vivía en un sector rural, cifra que contrasta con la distribución nacional, donde $71 \%$ de la población radica en centros urbanos. El nivel de escolaridad que reportó este municipio es de 8.1 años, menor que el nivel de escolaridad nacional de 9.7 años. Además, 31 de cada 100 personas son hablantes de lengua indígena (INEGI, 2013).

Según las estadísticas, en 2017 solo $40.4 \%$ de los hogares oaxaqueños tenía acceso a internet, y en 2018 apenas $29.1 \%$ poseía una computadora, ${ }^{3}$ porcentaje que disminuía a $8.2 \%$ en las localidades rurales (Instituto Federal de Telecomunicaciones, 2019). Al cierre de este año, mientras que el promedio de la teledensidad móvil (líneas del servicio de telefonía móvil por cada 100 habitantes) a nivel nacional era de 96, Oaxaca (79), Guerrero (77) y Chiapas (73) reportaron las cifras más bajas (IFT, 2019).

En 2021 la revista CIO México publicó un estudio sobre conectividad que muestra las asimetrías de brecha digital. La Ciudad de México, Baja California y Nuevo León se posicionan como las entidades que cuentan con mayor conectividad a internet en los hogares ( $76 \%$ el primer caso y $70 \%$ los dos restantes), mientras que Guerrero, Oaxaca y Chiapas ocupan los últimos lugares, con $32 \%, 29 \%$ y $22 \%$ respectivamente (CIO México, 2021). ${ }^{4}$

La localidad rural de San Pedro el Alto se encuentra localizada a 29.3 kilómetros de la cabecera municipal de Zimatlán de Álvarez, Oaxaca. Para 2020

\footnotetext{
2 En México se consideran como localidades rurales aquellas que cuentan con una población inferior a 2500 habitantes (Soloaga, Plassot y Reyes, 2021).

${ }^{3}$ Esto contrasta con el porcentaje de la Ciudad de México (66\%) y el promedio que se registraba a nivel nacional $(45 \%)$.

${ }^{4}$ Al seguir esta tendencia, las entidades con menor incremento en disponibilidad de computadoras entre 2010 y 2020 fueron Oaxaca, Guerrero y Chiapas, las dos primeras con $20 \%$ y la última con 16\%. De 2010 a 2020 la disponibilidad de computadoras en los hogares pasó en promedio de $29 \%$ a $38 \%$ en el país, pero algunas entidades reportaron un amento mínimo: en Oaxaca apenas fue de $6 \%$, en Guerrero y Tabasco de $4 \%$ y en Chiapas de 3\% (CIO, 2021).
} 
tenía 925 habitantes; $25.73 \%$ de la población se reportó como indígena y tan solo $4.2 \%$ como analfabeta. El grado de escolaridad promedio que tienen es de 8.5 años. En el ámbito de la brecha digital se encontraron los siguientes datos relevantes: $4.31 \%$ de los hogares cuenta con computadora, mismo porcentaje que tiene teléfono fijo; en contraste, $42.58 \%$ de los habitantes cuenta con teléfono celular pero solo $8.61 \%$ tiene acceso a internet (PueblosAmerica.com, $\mathrm{s} / \mathrm{f}$ ). ${ }^{5}$

\section{Metodología}

La investigación realizada constituye un estudio de caso intrínseco de tipo exploratorio (Stake, 2005) que se desarrolló bajo un diseño mixto convergente con un alcance exploratorio-descriptivo, por ser un fenómeno poco explorado. Previo a la investigación empírica, se realizó un estudio documental para sentar las bases teórico-conceptuales; posteriormente se efectuó una visita a la comunidad para la identificar a los actores e informantes $y$, mediante la observación, levantar información sobre el contexto de la comunidad.

Los factores que incidieron en este proyecto se indagaron a través de entrevistas semiestructuradas aplicadas a seis actores clave (la selección de los informantes se realizó por conveniencia) (ver tabla 1).

Tabla 1. Actores e informantes clave

\begin{tabular}{|l|l|}
\multicolumn{1}{|c|}{ Informantes clave } & \multicolumn{1}{c|}{ Dependencia } \\
\hline $\begin{array}{l}\text { Informante 1. Representante administrativo } \\
\text { Informante 2. Vocal técnico }\end{array}$ & Rhizomática A.C. \\
\hline $\begin{array}{l}\text { Informante 3. Presidenta del comité } \\
\text { Informante 4. Encargada de oficina }\end{array}$ & $\begin{array}{l}\text { Comité de Telefonía Celular } \\
\text { Comunitaria }\end{array}$ \\
\hline $\begin{array}{l}\text { Informante 5. Agente municipal } \\
\text { Informante 6. Secretario de la agencia }\end{array}$ & Autoridades de San Pedro el Alto \\
\hline
\end{tabular}

Fuente: elaboración propia.

De igual forma, se levantó una encuesta para obtener datos cuantitativos. El cuestionario constó de diez preguntas organizadas en tres apartados: información sociodemográfica del encuestado; los mecanismos de acceso y el funcionamiento de la TCC; y la información relacionada con el aprendizaje y el desarrollo de competencias en materia de las TIC. El instrumento fue validado por expertos y se aplicó una prueba piloto para asegurarse de que las preguntas estuvieran bien estructuradas.

\footnotetext{
${ }^{5}$ Estas cifras pueden cotejarse con los datos de 2010, fecha en que $6.21 \%$ de los habitantes contaba con teléfono celular y solo $0.56 \%$ tenía acceso a Internet (PueblosAmerica.com s/f).
} 
Los participantes se eligieron mediante un muestreo aleatorio simple; el tamaño de la población fue de 130 personas, que equivale al número de usuarios de la TCC, y comprende hombres y mujeres entre 16 y 70 años. El valor del nivel de confianza fue de $95 \%$ y el margen de error de $5 \%$, dando como resultado una muestra de 97 personas. El tamaño de esta se determinó con base en Vallejo (2012), aplicando la siguiente formula:

$$
n=\frac{N * Z^{2} * p *(1-p)}{(N-1) * e^{2}+Z^{2} * p *(1-p)}
$$

Donde:

$\mathrm{N}$ es el tamaño de la población: 130

$\mathrm{a}_{\mathrm{c}}$ representa el valor del nivel de confianza (varianza): 95

e es el margen de error: $5 \%$

Sustituyendo en la fórmula, el resultado es el que aparece a continuación:

$$
n=\frac{130 * 1.96^{2} * 0.5 * 0.5}{(130-1) * 0.05^{2}+1.96^{2} * 0.5 * 0.5}
$$

Finalmente, el análisis de la TCC se efectuó con las variables de la acción pública, para conocer su diseño, implementación y funcionamiento, así como su contribución en la inclusión digital de San Pedro el Alto.

\section{Resultados}

\section{Factores habilitadores}

En los datos arrojados por las encuestas se observa que $57 \%$ de los usuarios de la TCC son mujeres, lo que indica que no existe una brecha digital de género (ver gráfica 1). En cuanto a la edad de los usuarios, 33\% tiene entre 16 y 25 años y $25 \%$ tiene entre 26 y 35 años, por lo que se puntualiza que la mayoría de los usuarios son individuos jóvenes, parte del sector productivo de la comunidad (ver gráfica 2). En la misma gráfica se observa que, al incrementar el rango de edad, el porcentaje de usuarios disminuye; por ejemplo, de 36 a 45 años (17\%), de 46 a $55(15 \%)$, de 56 a $65(8 \%)$ y 65 y más $(2 \%)$.

En tanto a la ocupación, se encontró que la mayoría de los usuarios (40\%) son personas que tienen algún empleo remunerado, ya sea en áreas de la salud, en la Agencia Municipal o en pequeños comercios. Los estudiantes ocupan el segundo sitio, con 36\%, y los jornaleros el último (1\%) (ver gráfica 3 ). 
Gráfica 1. Género de los usuarios de la TCC

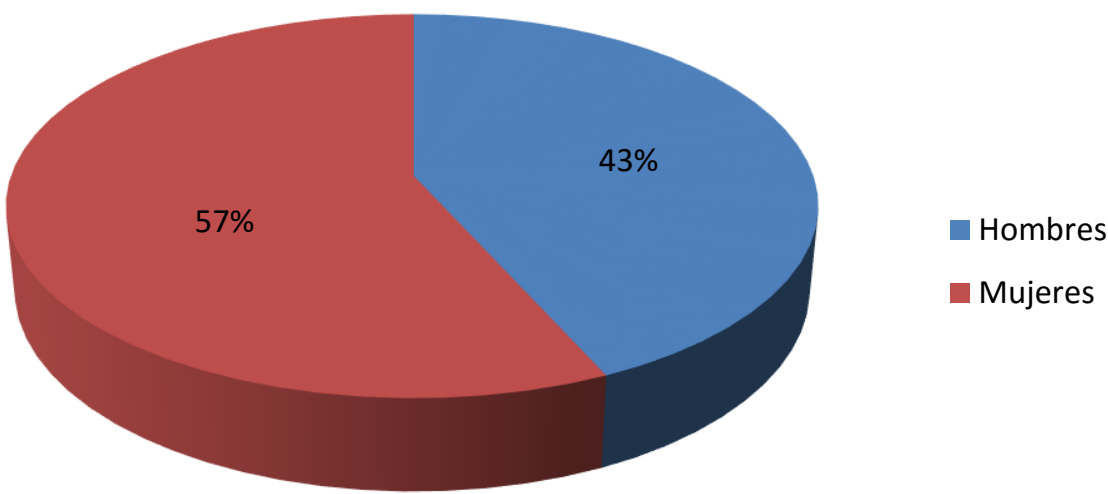

Fuente: elaboración propia.

Gráfica 2. Rango de edad de usuarios de TCC

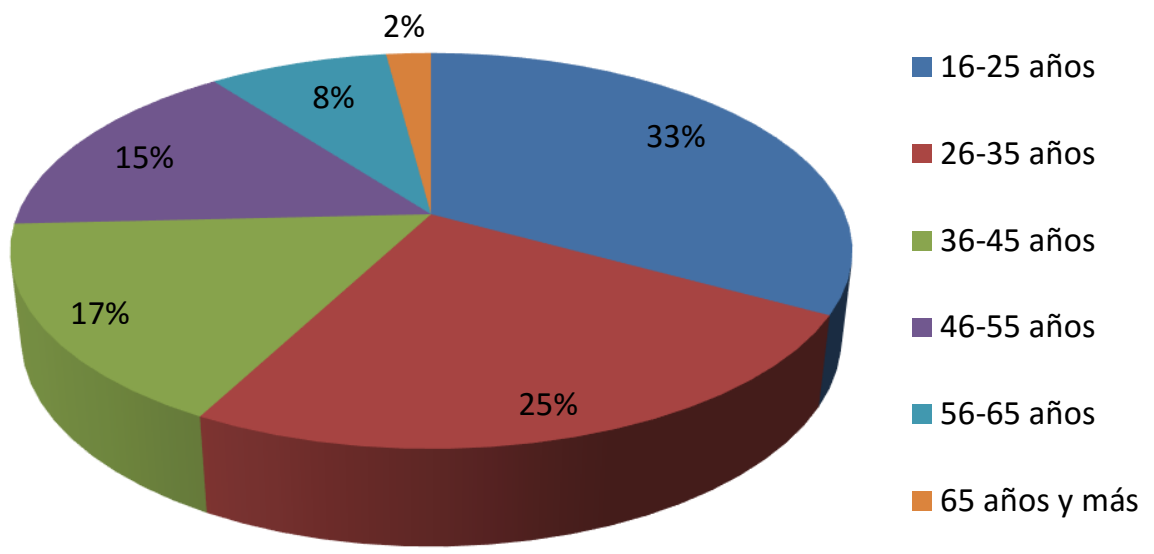

Fuente: elaboración propia. 
Gráfica 3. Ocupación de los usuarios de TCC

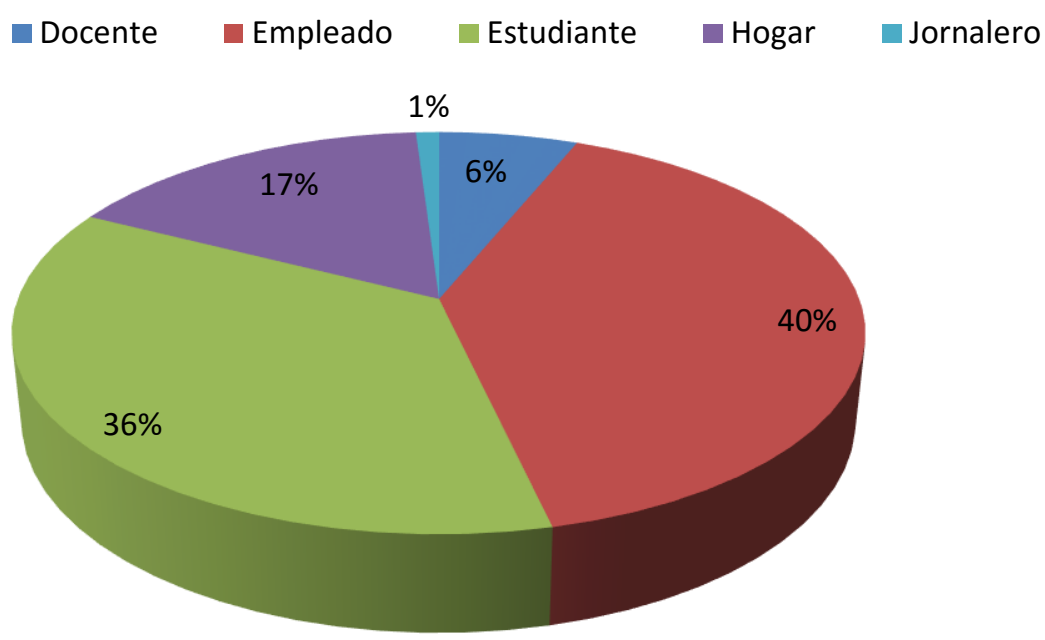

Fuente: elaboración propia.

\section{Factores del entorno}

En el análisis, se consideró como parte de los factores del entorno las personas o empresas que ofrecen servicios de telefonía en San Pedro el Alto, Zimatlán. Al respecto, se encontró que en la localidad hay algunas casetas de Telmex que ofrecen servicios de telefonía de pago por minuto. Ante la existencia de estas surgió un primer cuestionamiento: ¿cuáles fueron los factores que dieron origen a este modelo de telefonía como una alternativa para contribuir a la inclusión digital? El agente municipal señaló:

En la comunidad hay tres casetas de Telmex donde se pueden hacer llamadas locales o de larga distancia, pero la gente no se siente a gusto por la privacidad. Pero no había muchas opciones para nosotros, para poder elegir de entre las empresas que hay, las que pudieran brindar un mejor servicio. Es por eso que, en vista de que los de Telmex no nos respondían, decidimos ver qué pasaría si dejábamos que los de la organización Rhizomática nos apoyaran en la instalación de esta telefonía comunitaria. De este tipo de telefonía nos enteramos por una persona de aquí de la comunidad (Informante 5. Pérez, H., comunicación personal, 10 de marzo de 2020).

De acuerdo con los informantes, los servicios en las casetas de Telmex en San Pedro el Alto son deficientes, pues la zona no tiene cobertura de telefonía celular, además de que su precio es elevado. Con la intención de dar una solución a estos problemas, la población decidió promover la TCC. 


\title{
Factores de participación
}

Para conocer sobre los factores de participación en la operación de los servicios de la TCC, en las entrevistas se preguntó por el número de asambleas del comité y el número de usuarios que se implican en estas.

\begin{abstract}
Realmente no se convocan asambleas propias del comité, lo que sucede es que la información se expone en las asambleas que convoca el Agente Municipal. De hecho, son dos asambleas obligatorias al año; si es necesario atender algunos asuntos en particular, se hacen dos asambleas intermedias, pero la participación del comité en estas es muy poca. En las dos asambleas obligatorias sí se participa, como un punto establecido en el orden del día. En cuanto a la participación dentro de las asambleas, nosotros solo damos a conocer el número de pagos que se han realizado hasta ese momento y algunas de las recomendaciones que nos hacen en las capacitaciones que recibimos en la ciudad de Oaxaca (Informante 3, Zárate, C., comunicación personal, 10 de marzo de 2020).
\end{abstract}

Los entrevistados mencionaron que la información sobre el servicio y los costos de la TCC se brinda de manera personal, tanto a los usuarios como a las personas en general que estén interesadas. Al indagar en el número de clientes que contempla el modelo se comentó que "no se tiene un número específico, pero en promedio son 130 usuarios al mes, ya que algunos se dan de baja o dejan de pagar y otros renuevan su pago" (Informante 4. Antonio, M., comunicación personal, 10 de marzo de 2020).

Las respuestas obtenidas también dejan entrever que es necesario perfeccionar la calidad del servicio, así como trabajar en los aspectos técnicos de la telefonía, mejoras que tendrían un impacto positivo en la demanda del servicio. "Creo que sí influye mucho la calidad de las llamadas; si hubiera cobertura la mayor parte del día, de forma más constante, creo que habría más personas registradas como usuarias, pero a veces falla mucho el servicio y eso hace que uno se disguste" (Informante 5. Pérez, H., comunicación personal, 10 de marzo de 2020).

Una de las precisiones que se hizo en este aspecto fue que el tipo de tecnología que utilizan en la comunidad no permite la conexión a internet, solo a los servicios de telefonía.

\section{La acción pública}

De los datos obtenidos por medio de las encuestas y las entrevistas, pueden analizarse algunas de las variables del pentágono de la acción pública propuesto por Lascoumes y Le Galés (2013). Debido a que un aspecto importante de la acción pública son las instituciones, se inquirió con los informantes si existen normas, reglamentos o manuales operativos internos del comité sobre la TCC, y 
si proporcionan algún tipo de asesoramiento para el uso de los dispositivos celulares del servicio.

Dentro del comité no existe ningún reglamento escrito que pueda guiar las actividades que se realizan, pero nosotros ya sabemos cómo trabajamos. En cuanto al asesoramiento a los usuarios, eso sí está disponible todo el tiempo, incluso hasta en horarios fuera del trabajo. Se les explica de manera detallada cómo deben usar el equipo telefónico y cuáles son las teclas que debe presionar cuando hay deficiencias en las llamadas. En caso de que sea una persona que no sabe leer, lo hago yo misma en ese momento, y si vuelven a acudir, lo hago de nuevo (Informante 4. Antonio, M., comunicación personal, 10 de marzo de 2020).

Al revisar el criterio de representaciones, se considera necesario que se fortalezcan aspectos de este modelo de telefonía. A pesar de que el comité de TCC de San Pedro el Alto asiste regularmente a las capacitaciones impartidas por Rhizomática y brinda asesoramiento sobre el uso de equipos telefónicos, debe mejorarse la delimitación de los reglamentos internos, los procesos de las asesorías técnicas y los mecanismos de información e interacción con los usuarios.

Ante la pregunta sobre la asistencia de los comités a las capacitaciones que brinda la organización, el vocal técnico de Rhizomática señaló lo siguiente:

La mayoría de los comités asisten a las capacitaciones, a aquellos que por alguna razón no pueden venir, les enviamos información por medios alternos, o nosotros asistimos a la comunidad. En el caso particular del comité de la Sierra Sur, es uno de los comités que más asiste a las capacitaciones que se programan. Y, la mayoría de las veces se aprecia que San Pedro el Alto es una de las comunidades que refleja mejor organización (Informante 2. Orozco, R., comunicación personal, 22 de febrero de 2020).

En el criterio de procesos se consideró la toma de decisiones de los usuarios de la TCC, con especial atención en la interrogante de si las personas sienten que este servicio les pertenece. La presidenta del comité de TCC comentó que:

Las personas de la comunidad fueron las que decidieron si este modelo de telefonía se implementaba o no. Ahorita ya se sienten identificadas con este tipo de telefonía. Por ejemplo, en cuanto a la infraestructura, las personas la cuidan y respetan el lugar donde se encuentran las antenas, [también] estuvieron de acuerdo con que se designara a una persona como velador para proteger las cosas todo el día. Es cierto que se presentan muchas fallas en el servicio, pero también es cierto que este servicio saca de apuros a muchas de las personas cuando se presentan emergencias. (Informante 3, Zárate, C., comunicación personal, 10 de marzo de 2020).

De acuerdo con las evidencias, se puede observar que la movilización de los actores, así como sus dinámicas de intercambio y su evolución, coinciden con lo planteado en el modelo de acción pública. Con el paso del tiempo, los usuarios se apropian del servicio y aprovechan las asambleas comunitarias para deliberar y tomar decisiones relacionadas con la TCC. Además, el trabajo de las autoridades 
de la comunidad y del comité contribuye a la integración social, a la par que dan solución a los problemas técnicos y administrativos del servicio.

Dentro del criterio de resultados, y con el objetivo de conocer la razón tras la adopción de la TCC, se formuló la pregunta: ¿cuál fue la intención de implementar este modelo de telefonía en los municipios indígenas de Oaxaca?

\begin{abstract}
Este proyecto no surge con el afán de competir con las empresas grandes que ofrecen el servicio de telefonía celular. Surgió con la idea de comunicar a las comunidades indígenas en donde no hay este servicio, [la TCC] representa una alternativa para que las comunidades puedan acceder a la telefonía celular. Hay otras maneras de hacerlo, a través de un satélite o hay muchas comunidades que tienen telefonía fija, pero el problema es que tendrían que pagar costos elevados para realizar sus llamadas telefónicas y [estas] tienen un tiempo limitado.
\end{abstract}

Lo que nosotros hemos buscado es desarrollar una tecnología que permita bajar el costo del servicio y contribuir a la economía de las comunidades; además, la telefonía celular comunitaria, a diferencia de la telefonía comercial, es de la comunidad, ellos compran sus equipos a través de las agencias municipales o de autoridades comunales o entre las dos, [que] generalmente están divididos, pero al final trabajan para el mismo fin. Lo que hacen es que se reúnen, juntan los recursos y se organizan para realizar la compra del equipo (Informante 2. Orozco, R., comunicación personal, 22 de febrero de 2020).

Al revisar de manera general la información obtenida en las entrevistas, se deduce que Rhizomática encuentra que los resultados de la TCC han sido positivos en las comunidades en las que se ha implementado el modelo. Los representantes de la asociación señalaron que recorren con regularidad las comunidades para brindar asesorías a los comités y verificar que las redes estén en buen estado.

\title{
Uso de las TIC por los usuarios de la TCC
}

Los resultados de la encuesta muestran un panorama general sobre el acceso a las TIC en San Pedro el Alto, Zimatlán. La totalidad de los encuestados dispone de un teléfono celular, pero solo $16.5 \%$ cuenta con una computadora; asimismo, $34 \%$ tiene acceso a la radio y $60.8 \%$ a la televisión digital (ver gráfica 4 ). Quienes manifestaron no disponer de computadora, radio o televisión aseguraron que esto se debe a la falta de recursos económicos.

En el rubro de la comunicación, $83 \%$ de los usuarios de la TCC puede hacer una Ilamada telefónica, 56\% puede enviar un mensaje de texto, 54\% grabar un audio y $58 \%$ tomar una foto (ver gráfica 5 ). Sin embargo, se observa que los usuarios no tienen las habilidades necesarias para utilizar tecnologías digitales ni para navegar en la red, lo cual habla de la existencia de una brecha cognitiva y, por tanto, de una oportunidad de mejora en términos de alfabetización digital. 
Gráfica 4. Acceso a las TIC de los usuarios de TCC

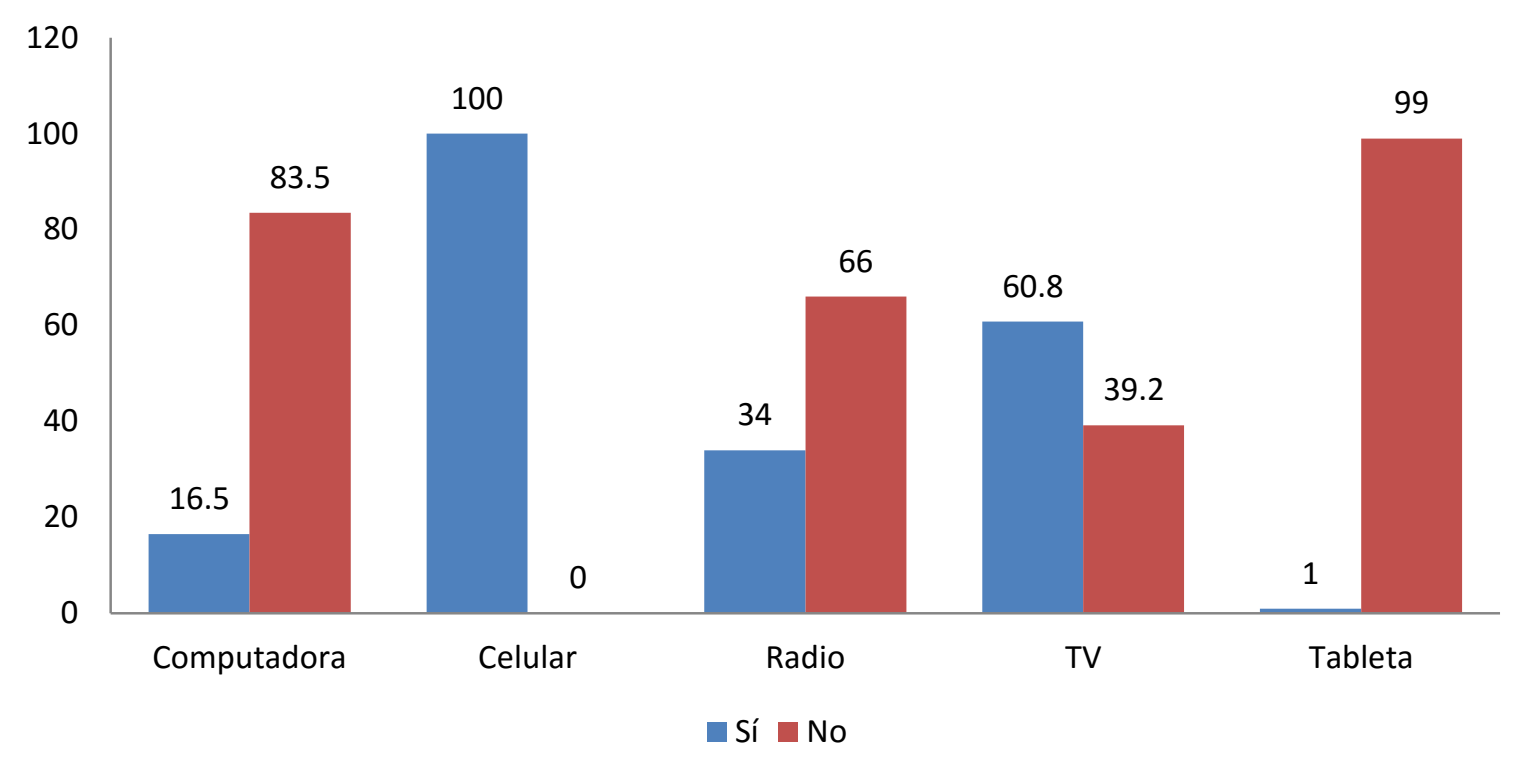

Fuente: elaboración propia.

Gráfica 5. Habilidades digitales de los usuarios de TCC

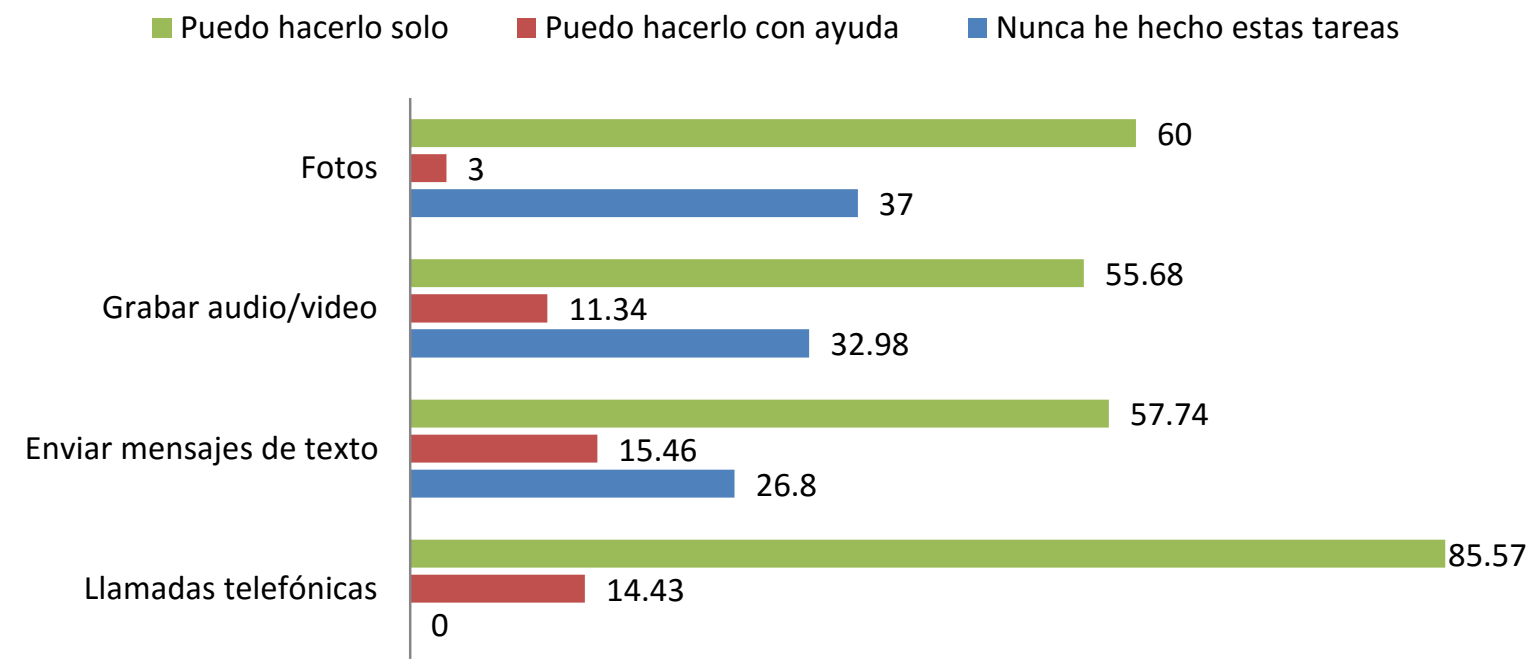

Fuente: elaboración propia.

Respecto al uso efectivo de servicios de TCC, 36\% de los usuarios señaló que los utiliza muy poco, 27\% que algunas veces a la semana, $18 \%$ que algunas veces al mes, y solo $19 \%$ señaló que los utiliza todos los días (ver gráfica 6 ). Esto pone en evidencia que en la localidad no hay un uso intensivo de la TCC. 
Gráfica 6. Uso efectivo a servicios de la TCC

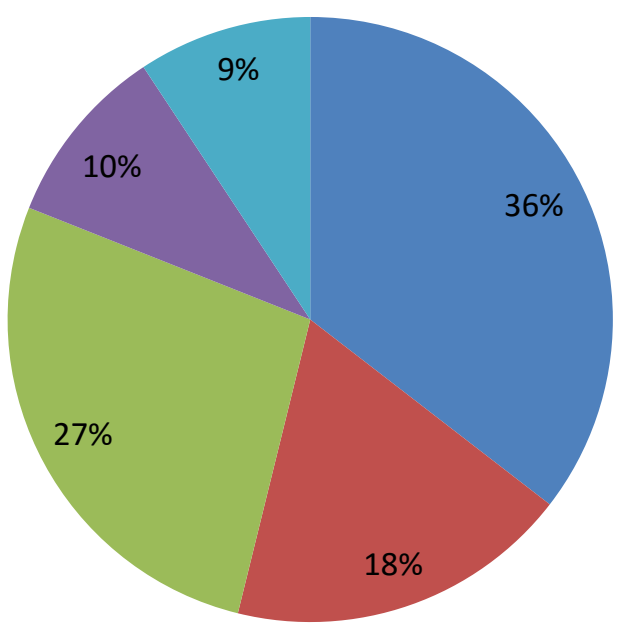

- Muy poco

Algunas veces al mes

Algunas veces a la semana

Diariamente, menos de dos horas al día

- Diariamente, dos horas o más al día

Fuente: elaboración propia.

\section{Impacto de la TCC en los usuarios}

Al preguntar a los usuarios sobre el impacto de la TCC en la mejora de su calidad de vida, $17.53 \%$ de las mujeres y $28.87 \%$ de los hombres considera que aportó poco a sus vidas. Por su parte, la percepción de que no hubo ninguna mejora en su cotidianidad es mínima, apenas $4.12 \%$ de los hombres y $6.19 \%$ de las mujeres hizo este señalamiento (ver gráfica 7).

Gráfica 7. Percepción de mejoramiento del nivel de vida generado por la TCC

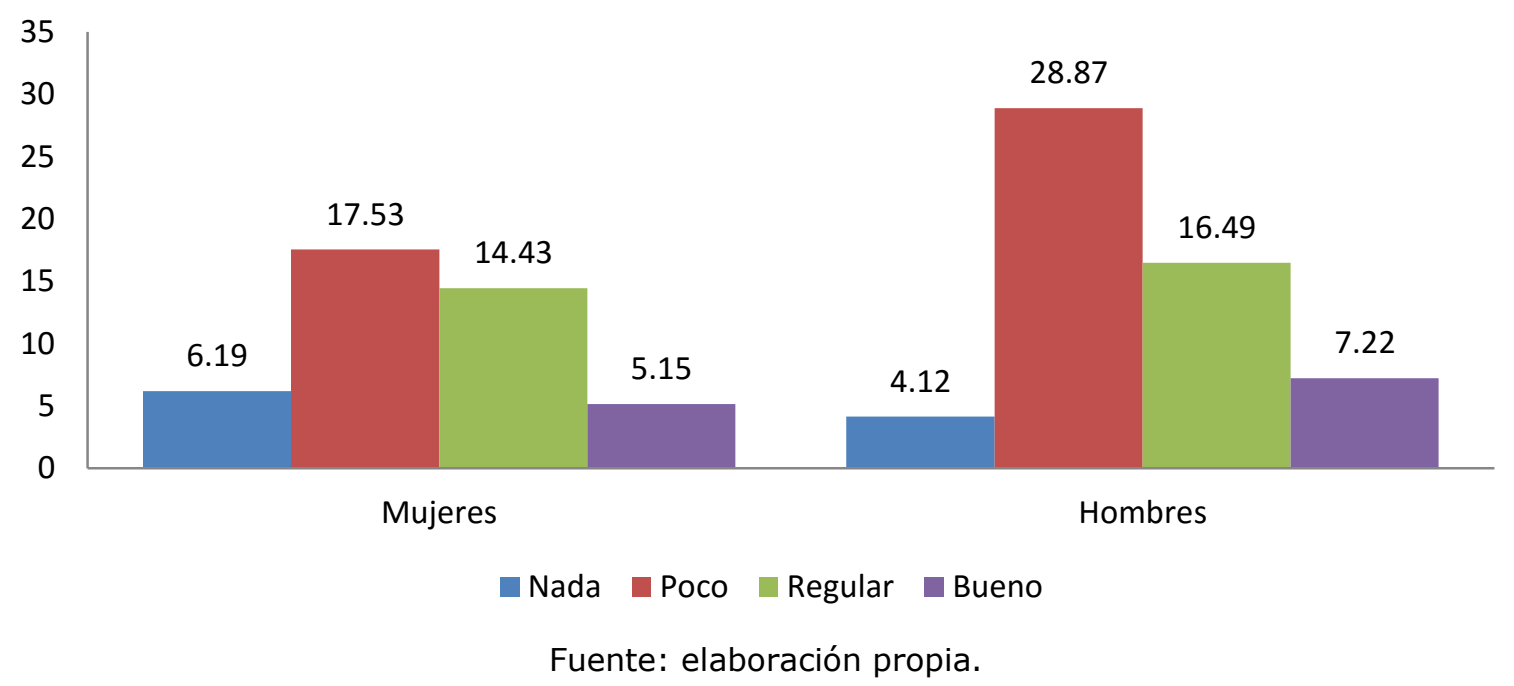

El nivel de estudios de los usuarios se considera relevante, pues se encuentra una relación directa de este con el uso de la TCC. La mayor parte de los usuarios solo 
cuenta con estudios de nivel primaria (41.18\%) y secundaria (36.78\%). En contraste, se evidenció que los usuarios con bachillerato $(16.6 \%)$ y estudios universitarios $(2.2 \%)$ representan una minoría. En la gráfica 8 se aprecia la frecuencia de uso de la TCC por nivel de estudios; los usuarios que la utilizan diariamente dos horas o más al día cuentan con primaria y secundaria. De igual forma, quienes mencionaron que casi nunca utilizan la TCC cuentan solo con estudios de primaria $(28.8 \%)$ y secundaria $(46.6 \%)$. Los usuarios con estudios universitarios (2.2\%) manifestaron usar la TCC algunas veces a la semana.

Gráfica 8. Uso de la TCC por nivel de estudios

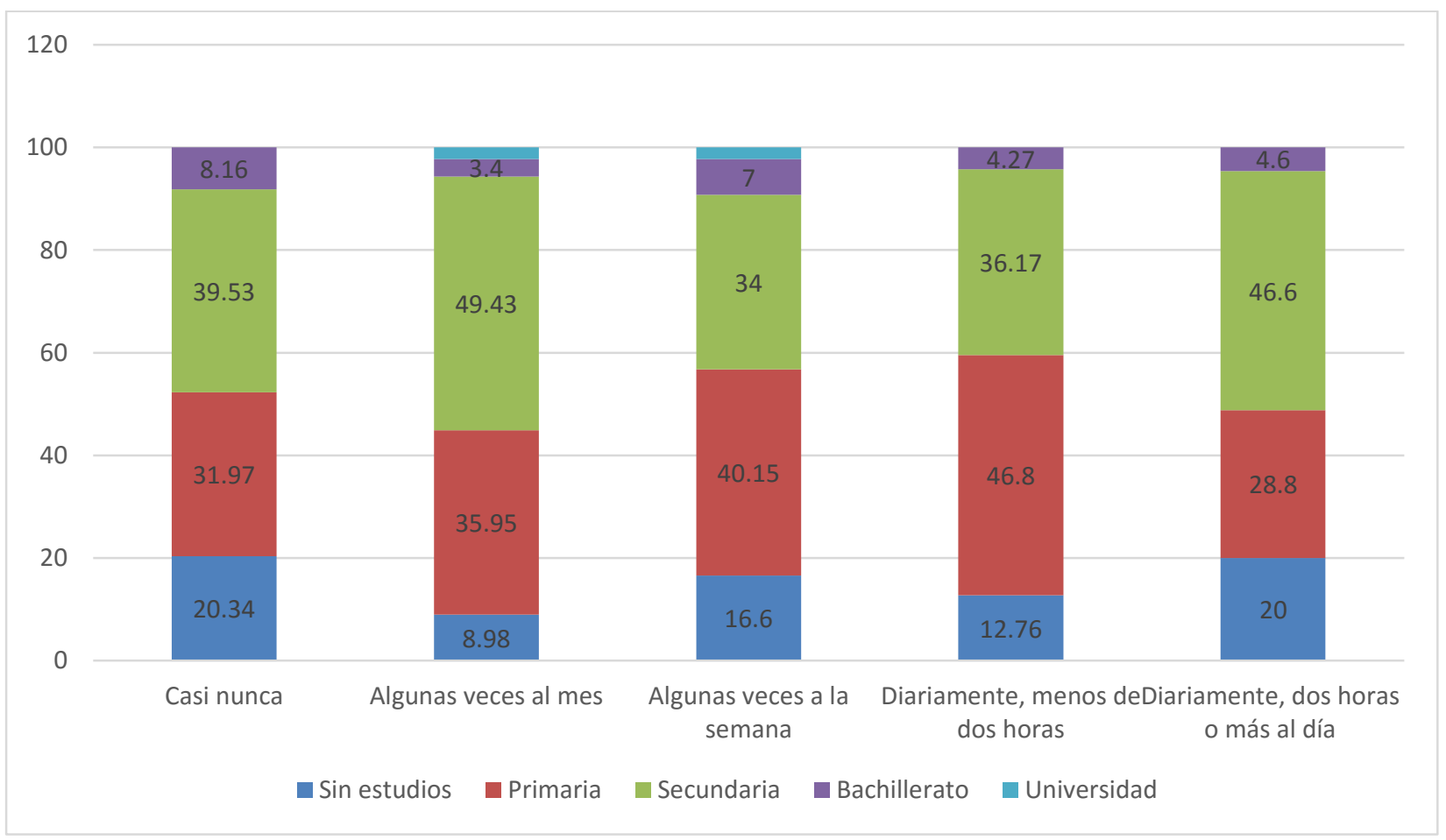

Fuente: elaboración propia.

\section{Discusión y conclusiones}

La TCC es una alternativa viable para la comunicación e interacción en comunidades rurales con pobreza económica y marginación social, problemas que aportan a la brecha digital. Esto se fundamenta en dos razones; en primer lugar, la TCC implica un bajo costo para los usuarios, y en segundo, sirve para mejorar la integración social, la inclusión digital, la colaboración y el desarrollo de habilidades básicas para el manejo de las TIC.

Tras realizar el proyecto se llegó a la conclusión de que la TCC no es una opción para impulsar la transición a la SI, debido a que los usuarios no tienen acceso a la red. A pesar de esto, en necesario resaltar que este modelo de telefonía cubre parcialmente una de las necesidades fundamentales de comunicación, por 
lo que es posible percibirlo como un mecanismo para el empoderamiento de las comunidades, que tiene potencial para mejorar la calidad de vida de sus usuarios a través de la comunicación.

Respecto a los niveles de educación, es evidente que existe una correlación entre estos y el desarrollo de la SI. Como se observó, parte importante de la población del caso de estudio cuenta con educación básica (primaria $41.18 \%$ y secundaria $36.78 \%$ ) y la población con estudios más elevados es menor (bachillerato $16.6 \%$ y universitarios $2.2 \%$ ). Esto se puede traducir en condiciones limitadas de educación, lo que obstaculiza que, como grupo, se alcance la SI y, por tanto, dificulta el acceso a los beneficios que trae el desarrollo social y económico. Para solucionar esto, se ve como necesario incrementar las condiciones de educación de la población.

Por otro lado, la investigación dejó al descubierto que parte de los usuarios de la TCC en San Pedro el Alto carece de habilidades para utilizar las TIC o navegar en la red, lo que indica la existencia de una brecha cognitiva y un rezago en la alfabetización digital. Esto es especialmente interesante al considerar que la mayoría de los usuarios ( $58 \%$ ) son jóvenes de entre 16 y 35 años, cuya relación con la TCC tiene el potencial de mejorar sus habilidades tecnológicas.

Como se mencionó anteriormente, el modelo de TCC resultó ser la única alternativa para la inclusión digital de la comunidad en San Pedro el Alto, Zimatlán, ya que no existía (ni existe aún) una competencia en el ramo del a telefonía celular capaz de brindar cobertura a todo el territorio. Por esta situación se considera que los factores del entorno no fueron determinantes en la implementación de esta alternativa. Al contrario, los resultados muestran que el factor de participación influyó de manera considerable en la introducción de la TCC, debido a que la consulta y la toma de decisiones se efectuaron directamente en las asambleas comunitarias, en las que todas las personas interesadas en el servicio podían participar.

Los ejes principales de la acción pública emprendida a través de la TCC fueron los actores y la participación social, lo que cumple con las premisas de la acción pública señaladas en los referentes teóricos. Los actores que participaron en el proyecto de TCC corresponden a los sectores público (autoridades de la Agencia Municipal, que contribuyeron a través de la autoridad política y la capacidad de gestión y coordinación de la toma de decisiones por medio de la asamblea comunitaria), social (ciudadanía en general, que intervino en la toma de decisiones y proporcionó los recursos necesarios para la adquisición de equipos) y privado (Rhizomática A. C., organización que aportó la experiencia y los conocimientos técnicos y que brinda la asesoría y capacitación técnica).

En la actualidad, la operación del servicio de TCC también depende en gran medida del comité de usuarios que interviene en la administración operativa del servicio y de las representaciones, encargado de promover una cultura de apropiación del modelo de TCC mediante el control, la administración y la operación 
técnica. Por ende, las representaciones son la esencia tanto de la integración social y de la inclusión digital, como de la apropiación social del servicio.

Si bien el criterio de las instituciones no se implementó como tal, no ha sido un factor determinante en la implementación y operación del modelo de TCC, ya que la Agencia Municipal de San Pedro el Alto se rige tradicionalmente por usos y costumbres, es decir, a través de reglas y normas internas de carácter informal, denominadas sistemas normativos indígenas.

Uno de los aspectos negativos (o al menos neutrales) de la TCC es que esta no influye en las tareas agrícolas, la principal actividad económica de la comunidad; esto se debe a que los trabajadores del campo casi no utilizan los servicios de telefonía, muestran poco interés en el tema y perciben que esta no mejora su calidad de vida. Otro factor negativo es que la TCC está marcada por la diferencia: $57 \%$ de las viviendas no tiene acceso al teléfono celular. Esto significa que más de la mitad de la población no puede comunicarse o interactuar a través de la TCC, lo que propicia una brecha tecnológica entre los que tienen acceso a este servicio y los que no lo tienen, situación que constituye una desigualdad social.

Finalmente se señala que la brecha digital o tecnológica es un fenómeno que seguirá presente en las comunidades rurales marginadas, en tanto los servicios de internet y de telefonía celular estén en manos del mercado. Por tal razón, el modelo de TCC que está operando en la Agencia de San Pedro el Alto, del municipio de Zimatlán, Oaxaca, resulta una alternativa viable para la inclusión digital y para reducir la desigualdad social, siempre y cuando la cobertura se extienda a todas las viviendas de la comunidad.

Se recomienda que el modelo de la TCC se promueva en otras comunidades rurales de Oaxaca que presentan problemas de brecha digital, ya que se trata de una alternativa de inclusión digital que, además del bajo costo que representa, sirve para promover la participación social y la integración comunitaria, así como la colaboración entre los sectores público y privado.

\section{Referencias}

Abdulwakeel, S. (2017). What is rurality. Livelihood and Conflict View Project. https://www.researchgate.net/publication/319123136 WHAT IS RURALITY

Alva de la Selva, A. (2015). Los nuevos rostros de la desigualdad en el siglo XXI: la brecha digital. Revista Mexicana de Ciencias Políticas y Sociales, 60(223), 265-285. http://dx.doi.org/10.1016/S0185-1918(15)72138-0

Amaya, V. M. (2010). Acción pública, instituciones y efectividad de los mecanismos de cooperación en el sistema de gestión del agua de Aguascalientes. Gestión y Política Pública, XIX(1), 37-77. http://www.scielo.org.mx/pdf/gpp/v19n1/v19n1a2.pdf

Ashley, C. \& Maxwell, S. (2001). Rethinking Rural Development. Developed Policy Review, 19(4), 395-425. https://library.fes.de/libalt/journals/swetsfulltext/12093116.pdf

Barba Solano, C. (2011). Revisión teórica del concepto de cohesión social: hacia una perspectiva normativa para América Latina. En Perspectivas críticas sobre la 
cohesión social: desigualdad y tentativas fallidas de integración social en América Latina (pp. 67-86). Buenos Aires: CLACSO. https://core.ac.uk/download/pdf/35175134.pdf

Blau, P. M. (1960). A Theory of Social Integration. The American Journal of Sociology, 65(6), 547-556. https://doi.org/10.1086/222785

Cabrero, M. (2009). Acción pública y desarrollo local. México: CIDE.

Camas Baena, V. (2014). El comunitarismo como estilo de vida en vías de desaparición. Sociología del Trabajo, (82), 51-72. https://recyt.fecyt.es/index.php/sociologiatrabajo/article/view/54748

Carbajal, V. (2009). Inclusión o exclusión social: el reto de las TIC y el caso de las poblaciones rurales centroamericanas. Apuntes alrededor de la experiencia. Hekademus: Revista Científica de la Fundación Iberoamericana para la Excelencia Educativa, 2(5), 44-64. https://dialnet.unirioja.es/descarga/articulo/3287520.pdf

Chigbu, U. E. (2013). Territorial Development: Suggestions for a New Approach to Rural Development in Nigeria. https://doi.org/10.13140/RG.2.1.1744.3602

Chuaqui, J.; Mally, D. y Parraguez, R. (2016). El concepto de inclusión social. Revista de Ciencias Sociales, (69), 157-188. https://doi.org/10.22370/rcs.2017.69.927

CIO México. (2021). Censo INEGI 2020: Levantamiento innovador y brecha digital en los estados. Revista CIO México. https://cio.com.mx/censo-inegi-2020-levantamientoinnovador-y-brecha-digital-en-los-estados/

Diario Oficial de la Federación. (2001). Plan Nacional de Desarrollo 2001-2006. http://www.dof.gob.mx/nota detalle.php?codigo $=766335 \&$ fecha $=30 / 05 / 2001$

Esteban González, C. (2016). La concepción de lo público en el pensamiento de Hannah Arendt (trabajo de fin de máster). Facultad de Filosofía y Letras, Universidad de Valladolid.

https://uvadoc.uva.es/bitstream/handle/10324/18458/TFM F 2016 3.pdf?sequenc $\underline{e}=1$

Garzón, E. (2003). Lo íntimo, lo privado y lo público. Cuadernos de transparencia, No. 6. México: Instituto Federal de Acceso a la Información (IFAI). https://www.pjenl.gob.mx/CJ/CursosSicavi/To\%C3\%B1ita/Archivos\%20transprenci a/ARCHIVOS\%201/Lo\%20\%C3\%ADntimo, \%20lo\%20privado\%20y\%20lo\%20p\%C 3\%BAblico.pdf

Hargittai, E. (2003). The digital divide and what to do about it. En D. C. Jones (ed.), New Economy Handbook (pp. 822-841). San Diego, CA: Academic Press. http://www.webuse.org/pdf/Hargittai-DigitalDivideWhatToDo2007.pdf

Huerta Velázquez, E. y Lawrence Blomm, P. (2017). Manual de Telefonía Celular Comunitaria. Conectando al siguiente billón. México: Redes por la Diversidad, Equidad y Sustentabilidad A. C. / Telecomunicaciones Indígenas Comunitarias A. C.Rhizomatica. content/uploads/media/uploads/documentos/manual-tic-esp-final.pdf

Instituto Federal de Telecomunicaciones (IFT). (2019). Anuario Estadístico 2018. México: IFT.

http://www.ift.org.mx/sites/default/files/contenidogeneral/estadisticas/anuarioesta distico2018-111018.pdf

ITU. (2016). ¿Cómo colmar la brecha digital de género? ITU News Magazine, No. 04/2016. https://www.itu.int/en/itunews/Documents/2016-04/2016 ITUNews04-es.pdf

Instituto Nacional de Estadística y Geografía (INEGI). (2013). Perfil sociodemográfico Estados Unidos Mexicanos. https://inegi.org.mx/app/biblioteca/ficha.html?upc $=702825047610$

Jones, C. O. (1970). Introduction to the study of public policy. Belmont, California: Wadsworth Pub. 
Jordán, V.; Galperin, H. y Peres Núñez, W. (coord.). (2013). Banda ancha en América Latina: más allá de la conectividad. Chile: Comisión Económica para América Latina y el Caribe. https://repositorio.cepal.org/bitstream/handle/11362/35399/S2013070 es.pdf?seq ue

Keniston, K. \& Kumar, D. (ed.). (2003). The four digital divides. Delhi: Press at Sage Publishers.

http://www.itfind.or.kr/ITRPT/four\%20digital\%20divide 2003 mitpdf\%5B1\%5D.p $\underline{\mathrm{df}}$

Kvasnicova, T.; Kremenova, I, \& Fabus, J. (2016). From an analysis of e-services definitions and classifications to the proposal of new e-service classification. Procedia Economics and Finance, 39, 192-196. https://doi.org/10.1016/S2212$\underline{5671(16) 30282-9}$

Lascoumes, P. y Le Galés, P. (2013). Sociología de la acción pública. México: El Colegio de México.

Lemmens, R. (2006, September). Semantic interoperability of distributed geo-services (tesis). International Institute for Geo-Information Science and Earth Observation. https://research.utwente.nl/files/31027509/Lemmens thesis.pdf

Peters, G. (2003). El nuevo institucionalismo: teoría institucional en Ciencia Política. Barcelona: Gedisa.

PueblosAmerica.com. (s/f). San Pedro el Alto (Zimatlán de Álvarez, Oaxaca). https://mexico.pueblosamerica.com/i/san-pedro-el-alto-5/\#poblacion

Ramírez Castañeda, L. y Sepúlveda López, J. (2018). Brecha digital e inclusión digital: fenómenos socio-tecnológicos. Revista EIA, 15(30), 89-97. https://doi.org/10.24050/reia.v15i30.1152

Ruano de la Fuente, J. (2002). La gobernanza como forma de acción pública y como concepto analítico. VII Congreso Internacional del CLAD, Lisboa, Portugal, 8-11. https://www.researchgate.net/publication/316455781

Selwyn, N. (2004). Reconsidering political and popular understandings of the digital divide. New media \& society, 6(3), 341-362. https://doi.org/10.1177/1461444804042519

Serrano, S. y Martínez, M. (2003). La brecha digital: Mitos y realidades. México: UABC.

Silver, H. (2015). The Contexts of Social Inclusion. Department of Economic \& Social Affairs. DESA Working Paper No. 144. New York: USA. http://dx.doi.org/10.2139/ssrn.2641272

Soloaga, I., Plassot, T. y Reyes, M. (2021). Caracterización de los espacios rurales en México a partir de estadísticas nacionales. CEPAL-FIDA. https://repositorio.cepal.org/bitstream/handle/11362/46350/7/S2100027 es.pdf

Stake, R. (2005). Qualitative case studies. En N. Denzin \& Y. Lincoln, The Sage handbook of qualitative research (pp. 443-466). London: Sage Publications.

Thoenig, J. (1997). Política pública y acción pública. Gestión y política pública, 6(1), 1937.

http://repositoriodigital.cide.edu/bitstream/handle/11651/3185/T] Vol.6 No.I 1sem.pdf?sequence= $\underline{1}$

Thompson, K. M.; Jaeger, P. T.; Taylor, N. G.; Subramaniam, M. \& Bertot, J. C. (2014). Digital literacy and digital inclusion: Information policy and the public library. Lanham: Rowman \& Littlefield.

Travieso, J. L. y Planella, J. (2006). La alfabetización digital como factor de inclusión social: una mirada crítica. UOC Papers: revista sobre la sociedad del conocimiento, (6). http://www.uoc.edu/uocpapers/6/dt/esp/travieso planella.pdf

Uslaner, E. \& Conley, R (2003). Civic engament and particularizad trust. American Politics Research, 31(4), 337-360. https://doi.org/10.1177/1532673X03031004001 
Zambrano Acosta, J. (2009). Las políticas públicas en TIC. Una oportunidad de cerrar la brecha social. Revista $\quad$, 4(7). https://repository.upb.edu.co/handle/20.500.11912/6575

Este artículo es de acceso abierto. Los usuarios pueden leer, descargar, distribuir, imprimir y enlazar al texto completo, siempre y cuando sea sin fines de lucro y se cite la fuente.

\section{CÓMO CITAR ESTE ARTÍ́CULO:}

Vásquez Ramos, M.; Soto Hernández, D. y Rentería Gaeta, R. (2022). Acción pública y telefonía comunitaria para la inclusión digital de comunidades rurales indígenas: el caso de San Pedro el Alto, Zimatlán, Oaxaca. Paakat: Revista de Tecnología y Sociedad, 12(22). http://dx.doi.org/10.32870/Pk.a12n22.674

* Licenciada en Administración Pública por la Universidad de la Sierra Sur, México. Líneas de interés: economía, sociedad y TIC. Correo electrónico: mine-94-ramos@hotmail.com

** Doctor en Finanzas Públicas por la Universidad Veracruzana, México. Adscrito al Departamento de Posgrado en la Universidad de la Sierra Sur-Oaxaca, profesor investigador de tiempo completo. Coordinador de Maestría y Doctorado en Gobierno Electrónico. Sus líneas de investigación comprenden el cambio tecnológico, la sociedad y el gobierno electrónico. Cuenta con perfil deseable del PRODEP. Correo electrónico: dsoto80@hotmail.com

*** Doctor en Gobierno Electrónico por la Universidad de la Sierra Sur, México. Maestro en Gestión Pública por la Universidad de Guadalajara, México. Profesor investigador de la Universidad de la Sierra Sur. Líneas de interés: TIC en la sociedad del conocimiento. Correo electrónico: rrenteria.gaeta@gmail.com 